\title{
Research on the "Five-dimensional Integration" Path of Constructing Media Convergence in Universities
}

\author{
Qilei He ${ }^{1, *}$, Siqi $\mathrm{Xu}^{1}$, Zhiyi $\mathrm{Yu}^{1}$, Hongwei Wang ${ }^{1}$, Tian Tang ${ }^{1}$ \\ ${ }^{1}$ Glasgow College, UESTC \\ ${ }^{*}$ Corresponding author. Email: heqilei@uestc.edu.cn
}

\begin{abstract}
Following the trend, campus media has been seeking a path to media convergence. Constructing media convergence in universities is in accord with the new development trends of media. It is beneficial to build a new pattern of publicity, construct campus culture, and develop service, communication and supervision functions. However, there are still several quagmires being faced, such as unbalanced development between traditional and new media, immature integrated development, more complicated regulatory issues in network public opinions and insufficient high-end professional talents. This paper is dedicated to demonstrating the significance of putting forward the "fivedimensional integration" from the perspective of media, institution, content, technology and talent.
\end{abstract}

Keywords: Universities, Media Convergence, Five-Dimensional Integration

\section{INTRODUCTION}

With the rapid development of Internet technology in recent years, the use of mobile terminals has been widely popularized. Meanwhile, contemporary communication has entered a new stage of rapid development as well. Thus, there is an urgent need to seek new forms and new carriers to realize resource integration and further tap the communication power and influence. So the idea of media convergence, which aims at conducting comprehensive and in-depth integration of different media forms with common ground and complementarity, such as network, radio, television and newspaper. emerge as the times require. In September 2020, General Office of the CPC Central Committee and General Office of the State Council published Opinions on Accelerating the Development of Deep Media Integration which defines the overall requirements for the development of in-depth media convergence[1]. Under the trend of further promotion of media convergence, colleges and universities media are trying to carry out the construction of convergent media as well, creating the communication matrix of campus convergent media, enhancing the influence of college media among teachers and students, and giving full play to the function of network culture in educating people.

\section{SIGNIFICANCE OF PROMOTING CONSTRUCTION OF UNIVERSITIES MEDIA CONVERGENCE}

\subsection{Accordant with the New Trend of Media Development}

Great innovation of science technology is always followed with significant changes and development transformation of media pattern. With changes of communication mode in the information age, it also has a great impact on people's production and life style. With the continuous development of information society, 5G, Big Data, Cloud computing, Internet of things, blockchain, AI and other information technology achievements make information transmission more convenient and prompt, so emerging media transfers from basic information acquisition to a public opinion platform that gathers information exchange, view point sharing and public opinion collection together. Due to its faster speed, richer content and higher interactive quality than traditional medias, new media has attracted a larger number of young users. From 2014, the media convergence between new and traditional media has experience its early exploration stage and accelerating advancing stage. After 2019, the development of media convergence comes to a more comprehensive stage and even construct a new era of all media. Constructing media convergence in universities is necessary, urgent, 
and accordant with the new trends of media development.

\subsection{Conducive to the Establishment of a New Pattern of Publicity}

The university campus media is one of the most important places in college propaganda work. Media convergence can promote universities to better integrate existing media resources, make an overall planning of content and path, broaden communication channels and paths, promote thematic and spread positive energy. On this basis, universities will gradually establish a comprehensive communication network from multiple angles which is participated by the public, shared by multi-departments and embraces full coverage. In a word, media convergence in universities is of great significance for the close contact and sincere cooperation between universities and departments to jointly build a new pattern of "big publicity" in universities, furthermore, it has a great positive impact on improving transmission, influence, guidance and credibility of publicity.

\subsection{Beneficial to the Construction of Campus Culture}

The university campus media is one of the main carriers in campus culture construction. Universities campus culture is a part of overall social culture and it illustrates a particular spiritual and cultural environment of the school. Constructing universities media convergence should apply methods that are loved by a broad audience to publicize university spirit and campus culture, as well as attract teachers and students to join campus culture construction, which adds a more sense of contemporaneity and color to campus culture activities that meet increasingly diverse ethical and cultural needs of teachers and students [2].

\subsection{Helpful to Develop Service, Communication and Supervision Functions}

The university campus media is one of the most principle platforms in serving teachers, students, staff and alumni. Universities media convergence can integrate and provide different kinds of information, as well as improve the efficiency of daily work to better serve teachers and students. Meanwhile, since new media has mutual communication function, media convergence is able to timely collect audience information and understand their demands to achieve interactive communication, which get the school and teachers, students, staff, society closer together. Also, it effectively achieves public opinion supervision by passing on the object from superior and reporting the situation to the top.

\subsection{Convenient to the Connection with Society}

Since media convergence has the advantage of openness and convenience across time and space, universities can realize effective interaction with society with the help of media convergence. On the one hand, it publicizes universities so that the society can better understand colleges and universities. On the other hand, the society can directly contact colleges and universities through financial media to realize the rapid connection between universities and society, which is convenient and efficient to realize the characteristics of serving the society.

\section{DIFFICULTIES IN THE CONSTRUCTION OF MEDIA CONVERGENCE IN UNIVERSITIES}

\subsection{Unbalance between Traditional Media and New Media under the Impact from Internet}

Some universities have gradually abandoned traditional media, such as school newspaper, campus radio and other media platforms when turning to the exploration of the media convergence. It is obvious that a large number of human resources and funds have been invested to operate Wechat, Weibo and other media platforms. The influence of traditional media declines gradually, causing the unbalance between traditional media and new media is increasing.

\subsection{Immature Integrated Development of Universities Media Convergence}

Nowadays, traditional media and new media coexist in universities. Traditional media includes official websites, school newspapers, school journals, campus broadcasting stations and campus TV stations. New media includes Weibo, WeChat, and Tik Tok platforms. Campus media convergence is now still in the exploratory stage, and most media contents just move from one platform to another, so it has not formed an actual integration development, furthermore, it results in homogenization problems and aesthetic fatigue.

\subsection{Imperfect Using System of Media Convergence in Universities}

Many universities do not have a comprehensive understanding and research about the use of media convergence, so they do not fully realize the purpose of using media convergence to spread positive energy and highlight the themes of the times. At present, the media convergence in universities is at an individualized state, with low overall activity. They cannot use mutual transformation and mutual evaluation to expand their influence, and the actual effect is worse than expected. 


\subsection{Complicated Regulatory Issues in Network Public Opinions}

In today's world, the phenomenon of "culture invasion" and "culture infiltration" are getting severe, multicultural and multiple ideas are also generating, so various opinions and values co-exist. The spread of new media is not limited by time and space anymore, which makes regulatory issues in network public opinions more difficult.

\subsection{Shortage of High-end Technical Talents in Media Convergence}

Management talents were found insufficient in the media convergence center. Supervisors and administrative leaders can only accumulate experience in practice since no standard rules in this field can be followed yet. Quite a few topics on media convergence still need further exploration.

Besides, new media requires higher quality of talent cultivation in media convergence in universities. In recent years, profound changes have been undergone in the production process and media communication mode. The process of shooting, editing, producing and publishing needs multiple platforms and terminals in the traditional media. With the rise of mobile media, all the process can be completed with a mobile phone. Technical talents that are working in this area are expected to have higher compatibility and technical skills. Student journalists should master even more comprehensive skills.

\section{4. "FIVE-DIMENSIONAL INTEGRATION" PATH OF CONSTRUCTING MEDIA CONVERGENCE IN UNIVERSITIES}

\subsection{Integration in Media Dimension: the Creation of a Hypermedia Platform for Multi- media Integration}

Although with the continuous development of Internet technology, the user of such traditional media as paper media is decreasing, it does not mean that paper media will be replaced by new media. Most traditional media is state media, so the published content are original, initial and authentic. Meanwhile, traditional media has more advanced communication concept, mature operating mechanism, sound supervision and accurate content. On the basis of analyzing the changes of users' needs, it should promote the integration of traditional media and modern media by optimizing content and innovating communication mode, creating a hypermedia platform for multi-media integration. For instance, many university newspapers and periodicals have been adopting the mode of simultaneous distribution of online and print newspapers. The latter ones focus on in-depth reports, online news on comprehensive reports, while new media puts particular emphasis on timeliness and freshness. Based on the continuous development of traditional media and supplemented by the innovation of media integration, campus media complement each other to form a multidimensional publicity matrix, thus, each campus media platform finds its own differentiated positioning in the integration process.

\subsection{Integration in Institutional Dimension: the Establishment of the Assembly Editing Mode of “Central Kitchen" Collection}

Under the leadership of the Party committee of the university, campus media are supposed to learn from social media and take the construction of mature county-level media convergence center as the blueprint. Through the integration of resources in all aspects, campus media can establish a center of media convergence with the integrated development of campus media as its own responsibility to build it into a "central kitchen" which is in line with the reality of news publicity in colleges and universities, realizing the concept, process, technology, product and talent integration of all kinds of campus media at all levels [3].

\subsection{Integration in Content Dimension: Strengthen Content Construction and Supply}

Due to the diverse communication forms of media convergence, form is emphasized more over content, and low publicity quality commonly appear. Universities media convergence should put more stress on content instead of form, make all media content accurate, professional and strong, gain the initiative to public opinion field, decline homogenization and enhance high-quality content, social influence and market shares.

\subsection{Integration in Technological Dimension: the Integration of Campus Media Technology with "Internet Plus"}

The new media platform on campus should explore the concept of "Internet plus", strengthen leading advanced technology, enhance the integrated usage of $5 \mathrm{G}, 4 \mathrm{~K} / 8 \mathrm{~K}$, Big Data, Cloud computing, Internet of things, blockchain and AI in each stages, seize the all media era high ground, insist on the principle of the teachers and students-oriented, give full play to universities media convergence as a bridge between teachers, students and parents, strengthen in-depth interaction by not only working on news communication, but also applying new technological methods to offer smart, convenient and personalized information services, which gives better user experience to teachers and students' work and life [4]. 


\subsection{Integration in Talent Dimension: Team Integration and Professional Talent Training}

Talents of high quality is the core competitive advantage of campus media. The construction of convergence media talent team is an important part of the deep integration and development of campus media. Campus media should strengthen the team construction by mobilizing the work enthusiasm of traditional media staff, making good use of the talent stock and avoiding brain drain. On the other hand, with the continuous update of new technologies, new technical talents needed by new media should be actively introduced to improve the increment of talents[5]. In addition, universities are the cradle of talent training, where explore and train convergence media talents, so universities should accurately cultivate convergence media talents or even establish convergence media colleges to educate qualified convergence media talents who are reliable and professional to the society.

\section{CONCLUSION}

Media convergence is the significant field for improving the quality of education and strengthening propaganda work in the university. Universities should carefully analyze the current situation and attach importance to the development of new media as well as the advantages of the traditional media. In addition, universities should actively adapt to the current trends of integrated development of the media, take full advantages of the media convergence, establish correct guidance, carry forward the theme of the times, spread positive energy and make a better use of the media convergence that contributes to showing school reputation, spreading campus information, promoting campus culture and providing services to the teachers and students.

\section{ACKNOWLEDGMENTS}

Research Findings on Network Ideological and Political Education Research Project (CJWSZ20-14) of Sichuan Education Department.

\section{REFERENCES}

[1] The General Office of the CPC Central Committee, The General Office of the State Council. (2020) The Opinions on Accelerating the Development of Deep Media Convergence. http://www.gov.cn/zhengce/2020-09/26/content 5547310.htm

[2] Zhang G.Q., Zhang P. On the Value of Campus Network Culture Construction in Universities [J]. Research on Continuing Education, 2012 (10): 116-118.
[3] Mu G. C., Li X. Q., Cui W. F. Development, Opportunities, Status and Countermeasures of Campus Media Convergence in Universities [J]. Journal of Shandong University of Technology (SOCIAL SCIENCE EDITION), 2021,37 (04): 7176.

[4] Zhai C. X. Problems and Countermeasures in the Construction of Campus Media Convergence Platform [J]. News Research Guide, 2017,8 (08): 294.

[5] Li H. R., An S. Y. Research on the Construction of University Media Convergence Center under the trend of Media Convergence [J]. China Higher Education, 2017,8 (08): 294. 